\title{
KANDUNGAN TOTAL FENOL DAN FLAVONOID DARI BUAH KERSEN (Muntingia calabura) SERTA AKTIVITAS ANTIOKSIDANNYA
}

\author{
Made Ratih Mettaswari Senet*, I Made Oka Adi Parwata dan I Wayan Sudiarta
}

Program Studi Kimia FMIPA Universitas Udayana, Bukit Jimbaran, Badung, Bali 80361

*Email: ratihmettaswari@yahoo.co.id

\begin{abstract}
ABSTRAK
Buah kersen (Muntingia calabura) merupakan salah satu buah yang memiliki manfaat tinggi untuk kesehatan dan dapat dikonsumsi sebagai alternatif pengganti obat. Penelitian ini bertujuan untuk mengetahui kandungan total fenol dan flavonoid dari buah kersen serta menguji aktivitas antioksidannya. Sampel buah kersen sebanyak 1,56 kg di ekstraksi secara bertingkat dengan metode maserasi menggunakan pelarut n-heksana, etil asetat, dan etanol yang menghasilkan ekstrak n-heksan $(2,16 \mathrm{~g})$, etil asetat $(4,52 \mathrm{~g})$, dan etanol $(50,25 \mathrm{~g})$. Hasil penapisan fitokimia menunjukan ekstrak etanol dan ekstrak etil asetat positif mengandung flavonoid dan fenol. Ekstrak etanol dan ekstrak etil asetat selanjutnya diukur kandungan total fenol dan flavonoidnya dengan metode spektrofotometri UV-Vis. Hasil pengukuran menunjukakan kandungan total fenol ekstrak etanol dan etil berturut-turut sebesar 0,24\% GAE dan 0,85\% GAE sedangkan kandungan total flavonoidnya berturut-turut $0,13 \%$ QE dan $0,03 \%$ QE. Aktivitas antioksidan ekstrak etil asetat dan etanol yang diukur dengan metode DPPH memberikan nilai IC 50 berturut-turut sebesar $0,13 \mathrm{mg} / \mathrm{mL}$ dan $0,25 \mathrm{mg} / \mathrm{mL}$.
\end{abstract}

Kata Kunci: Muntingia calabura, flavonoid, fenol, antioksidan

\begin{abstract}
Kersen fruit (Muntingia calabura) is considered as a fruit that has good benefit for health and can be consumed as an alternative medicine. This study aimed to determine total phenolic and total flavonoid contents as well as antioxidant activity of kersen fruit extract. The extraction of $1.56 \mathrm{~kg}$ kersen fruit gradiently using maceration method with n-hexane, ethyl acetate, and ethanol as solvents yielded $\mathrm{n}$-hexane extracts (2.16 g), ethyl acetate (4.52 g), and ethanol extract $(50.25 \mathrm{~g})$. The phytochemical testing showed that ethanol and ethyl acetate extracts contained flavonoid and phenolic compounds, therefore their total phenolic and flavonoid contents were determined using UV-Visible spectroscopy method. It was found that the total phenolic content of the ethanol and ethyl acetate extract was $0.24 \%$ GAE and $0.85 \%$ GAE respectively while the total flavonoid content of the ethyl acetate and ethanol extracts was $0.13 \% \mathrm{QE}$ and $0.03 \% \mathrm{QE}$ respectively. The antioxidant activity testing using DPPH method showed that $\mathrm{IC}_{50}$ value of ethyl acetate extract was $0.13 \mathrm{mg} / \mathrm{mL}$ and ethanol extract was $0.25 \mathrm{mg} / \mathrm{mL}$.
\end{abstract}

Keywords: Muntingia calabura, flavonoids, phenol, antioxidant

\section{PENDAHULUAN}

Indonesia merupakan salah satu wilayah tropis di dunia yang terkenal dengan keanekaragaman flora. Keanekaragaman tersebut menjadi salah satu pilar kekayaan Indonesia dan sejak dahulu sudah dimanfaatkan secara turun menurun sebagai obat traditional (Anonim, 2012). Seiring dengan munculnya slogan "back to nature" tanaman - tanaman tersebut dilirik kembali untuk diteliti dan dikembangkan sebagai bahan sediaan obat. Pemanfaatan tanaman obat dipercaya dapat menangkal berbagai penyakit yang dipicu akibat meningkatnya radikal bebas dalam tubuh (Sibuea, 2003).

Radikal bebas terdapat dalam tubuh merupakan bagian dari reaksi samping proses oksidasi seperti metabolisme dan dapat berasal dari luar tubuh sebagai akibat dari gaya 
hidup yang kurang sehat (Miller, 1996). Radikal bebas merupakan suatu atom atau molekul yang sangat reaktif dan tidak stabil karena memiliki elektron tidak berpasangan pada orbital terluarnya (Halliwel, 1991). Dalam menangani hal tersebut, diperlukan suatu substansi penting yang dapat menetralkan radikal bebas yangdikenal dengan antioksidan (Kunwar dan Priyadarsini, 2011)

Antioksidan merupakan salah satu senyawa yang dapat menetralkan radikal bebas dengan mendonorkan salah satu atom hidrogennya (Rauf, 2015). Keberadaan antioksidan dalam tubuh sebenarnya sudah tersedia dalam bentuk enzim yang dikenal sebagai antioksidan endogen, namun jumlah tersebut sering kali tidak seimbang dengan jumlah radikal bebas yang masuk ke dalam tubuh, sehingga diperlukan antioksidan eksogen (Panosvka dkk, 2005). Kebutuhan akan antioksidan eksogen memunculkan banyak produk berlebel antioksidan di pasaran, namun produk-produk tersebut dapat menimbulkan efek samping dalam pengkonsumsian jangka panjang. Dengan demikian, diperlukan senyawa antioksidan alami yang berasal dari tanaman (Widodo, 1997). Adapun salah satu tanaman yang mengandung senyawa yang bersifat antioksidan adalah Kersen (Muntingia calabura).

Kersen (Muntingia calabura) merupakan spesies tunggal dari Muntingia. Di Indonesia pemanfaatan buah kersen masih belum optimal karena dianggap tidak memiliki nilai ekonomis serta kurangnya pengetahuan mengenai pemanfaaatannya, padahal buah ini memiliki manfaat yang tinggi dan dapat dikonsumsi sebagai alternatif pengganti obat. Manfaat kersen sebagai obat dapat dilihat dari kandungan kimia buah kersen. Analisis fitokimia, ekstrak buah Kersen mengandung senyawa saponin, fenol, steroid/triterpenoid, dan flavonoid (Yunahara, 2009). Kandungan senyawa tersebut diantaranya memiliki aktivitas sebagai antioksidan yaitu fenol dan flavonoid, karena kemampuannya dalam mereduksi radikal bebas.

Kandungan senyawa tersebut sebagai antioksidan didukung oleh beberapa penelitian seperti kandungan senyawa fenolik pada kunir putih (Curcuma mangga Val) segar yang berpotensi antioksidan (Dwiyanti, 2010), daya antiosksidan senyawa flavonoid pada daun Plantago major L (Hertiani, 2000), golongan senyawa fenolik yang terdapat dalam hasil isolasi kulit batang kersen sebagai antioksidan (Alista, 2011) dan senyawa flavonoid pada kulit batang gayam sebagai antioksidan (Hany, 2016).

Berdasarkan latar belakang di atas, maka dilakukan penelitian terhadap kandungan total senyawa flavonoid dan fenol pada buah kersen (Muntingia calabura) serta aktivitasnya sebagai antioksidan alami dengan metode DPPH (1,1-difenil-2-pikrilhidrazil).

\section{MATERI DAN METODE}

\section{Bahan}

Bahan tumbuhan yang digunakan dalam penelitian ini yaitu buah kersen (Muntingia calabura L.) yang diperoleh dari wilayah Ubung. Bahan kimia yang digunakan dalam penelitian ini adalah etanol $\left(\mathrm{C}_{2} \mathrm{H}_{6} \mathrm{O}\right)$, 1,1-difenil-2-pikrilhidrazil (DPPH), metanol p.a, natrium hidroksida $(\mathrm{NaOH})$, Serbuk Magnesium $(\mathrm{Mg})$, Asam Klorida $(\mathrm{HCl})$, Aluminium Klorida $\left(\mathrm{AlCl}_{3}\right)$, Ferri Klorida $\left(\mathrm{FeCl}_{3}\right)$, n-heksan $\left(\mathrm{C}_{6} \mathrm{H}_{14}\right)$, etil asetat $\left(\mathrm{C}_{4} \mathrm{H}_{8} \mathrm{O}_{2}\right)$, aquadest, reagen Folin-Ciocalteu, $\mathrm{Na}_{2} \mathrm{CO}_{3}$, asam galat, dan quersetin.

\section{Peralatan}

Peralatan yang digunakan dalam penelitian ini adalah blender, neraca analitik, gelas beker, erlenmeyer, batang pengaduk, labu ukur, pipet volume, pipet tetes, pipet mikro, kertas saring, aluminium foil, tabung reaksi, corong gelas, penguap putar vakum (rotary vacuum evaporator), dan alat spekrofotmeter UV-Vis.

\section{Cara Kerja \\ Penyiapan Sampel}

Sampel buah kersen matang (Muntingia calabura) dikumpulkan dalam satu wadah kemudian dicuci hingga bersih. Sampel selnjutnya dimasukkan ke dalam alkohol panas dan di angin-anginkan di udara terbuka yang terlindungi dari sinar matahari langsung. Sampel buah kersen yang sudah bersih kemudian dihaluskan dengan menggunakan blender.

\section{Analisis Kadar Air Sampel}

Analisis kadar air buah kersen (Muntingia calabura) menggunkan metode oven. Cawan kosong dikeringkan dalam oven dengan suhu $105^{\circ}$ (selama 20-30 menit). 
Cawan kosong kering kemudian ditimbang dengan neraca analitik. Sebanyak 2,18 gram sampel dimasukkan kedalam cawan kering kemudian ditimbang dengan cepat. Cawan beserta sampel tersebut dikeringkan dalam oven $105^{\circ} \mathrm{C}$ selama $3 \mathrm{jam}$, setelah dioven selama 3 jam kemudian dimasukkan kedalam desikator selama 20-30 menit, lalu ditimbang kembali. Cawan dimasukkan kembali ke dalam oven sampai diperoleh berat yang konstan. Kadar air dalam sampel dapat dihitung dengan rumus berikut :

Kadar air $=\frac{(\text { beratawal }- \text { beratkonstan })}{\text { beratawal }} \times 100 \%$

\section{Ekstraksi dan Skrinning Metabolit Sekunder}

Sebanyak $1,56 \mathrm{~kg}$ buah kersen yang telah dihaluskan dimaserasi menggunakan pelarut dengan kepolaran yang meningkat mulai dari n-heksan, etil asetat dan etanol. Maserasi masing-masing pelarut dilakukan selama 9 hari dengan penggantian pelarut sebanyak 2 liter setiap 3 hari. Filtrat yang dihasilkan dikumpulkan dan dievaporasi dengan rotary evaporator (pada suhu $30^{\circ} \mathrm{C}$ ) sehingga diperoleh ekstrak pekat n-heksan. Residu yang sudah dikeringkan dari hasil maserasi dengan pelarut n-heksan kemudian dimaserasi berturut-turut dengan pelarut etil asetat dan etanol sehingga diperoleh ekstrak pekat etil asetat dan ekstrak pekat etanol. Masing-masing ekstrak dilakukan skrinning fitokimia flavonoid $(\mathrm{Mg}-\mathrm{HCl}$ dan $\mathrm{NaOH})$ dan fenol dengan metode Harborne (1996). Ekstrak yang positif fenol dan flavonoid selanjutnya diukur kandungan total fenol, total flavonoid dan aktivitas antioksidannya.

\section{Penentuan Kandungan Total Fenol}

Penentuan total fenol dilakukan dengan prosedur Riaminati dkk (2016) dengan beberapa modifikasi. Sebanyak 0,1 gram sampel (ekstrak etanol dan etil asetat) dimasukkan ke dalam labu ukur $5 \mathrm{~mL}$ dan diencerkan dengan metanol hingga tanda batas. Sampel selanjutnya divortex dan disaring untuk mendapatkan filtratnya. Sebanyak 100 $\mu \mathrm{L}$ filtrat dipipet dan di reaksikan dengan reagen follin sebanyak $100 \mu \mathrm{L}$. Larutan tersebut di vortex untuk menghomogenkan larutan, lalu didiamkan selama 6 menit. Ke dalam tabung tersebut kemudian direaksikan dengan $800 \mu \mathrm{L} \mathrm{Na}_{2} \mathrm{CO}_{3} 2 \%$, dihomogenkan lalu didiamkan 30 menit. Absorbansi selanjutnya diukur pada panjang gelombang
$760 \mathrm{~nm}$. Asam galat dibuat dengan konsentrasi 0-100 ppm sebagai kurva kalibrasi standar. Absorbansi sampel di interpolasi ke dalam persamaan regresi linear pada kurva standar.

\section{Penentuan Kandungan Total Flavonoid}

Penentuan total flavonoid dilakukan dengan prosedur Chang dan Wen (2002) dengan beberapa modifikasi. Sebanyak 0,1 gram ekstrak (etil asetat dan etanol) ditimbang. Sampel selanjutnya dilarutkan ke dalam labu ukur $5 \mathrm{~mL}$ menggunakan etanol $50 \%$ dan disaring. Filtrat yang dihasilkan kemudian direaksikan dengan $\mathrm{AlCl}_{3}$ dengan perbandingan 1:1 dengan cara $250 \mu \mathrm{L}$ ekstrak dipipet dan ditambahkan sebanyak $250 \mu \mathrm{L}$ etanol 50\%. Ekstrak tersebut dimasukkan pada tabung reaksi kemudian ditambahkan $500 \mu \mathrm{L}$ larutan $\mathrm{AlCl}_{3}$. Larutan selanjutnya dikocok hingga homogen dan didiamkan selama 30 menit. Pengukuran absorbansi dilakukan pada panjang gelombang $415 \mathrm{~nm}$. Kuarsetin dibuat dengan konsentrasi 0-100 ppm sebagai kurva kalibrasi standar Absorbansi sampel di interpolasi ke dalam persamaan regresi linear pada kurva standar.

\section{Penentuan Aktivitas Antioksidan}

Uji aktivitas antioksidan pada buah kersen dilakukan dengan metode DPPH (Blois, 1958). Sampel (ekstrak etil asetat dan etanol) dibuat konsentrasi induk $1 \mathrm{mg} / \mathrm{mL}$ atau $1000 \mathrm{ppm}$. Larutan induk selanjutnya dibuat variasi konsentrasi $0,05 \mathrm{mg} / \mathrm{mL}, 0,10 \mathrm{mg} / \mathrm{mL}$, $0,20 \mathrm{mg} / \mathrm{mL}$, dan $0,25 \mathrm{mg} / \mathrm{mL}$ dengan cara sampel dipipet sebanyak $20 \mu \mathrm{L}$ dan ditambahkan metanol $380 \mu \mathrm{L}$ ke dalam tabung 1, pada tabung 2 dipipet $40 \mu \mathrm{L}$ sampel dan ditambahkan metanol sebanyak $360 \mu \mathrm{L}$, pada tabung 3 dipipet $80 \mu \mathrm{L}$ sampel dan ditambahkan metanol sebanyak $320 \mu \mathrm{L}$, sedangkan pada tabung 4 dipipet $100 \mu \mathrm{L}$ sampel dan ditambahkan metanol sebanyak $300 \mu \mathrm{L}$. Masing-masing konsentrasi selanjutnya ditambahkan $400 \quad \mu \mathrm{L} \quad \mathrm{DPPH}$. Larutan di inkubasi dalam ruang gelap selama 30 menit. Serapan kemudian diukur pada panjang gelombang $517 \mathrm{~nm}$. Aktivitas penangkal radikal bebas pada ekstrak etil asetat dan etanol buah kersen (Muntingia calabura) di ekspresikan sebagai $\mathrm{IC}_{50}$. 


\section{HASIL DAN PEMBAHASAN}

\section{Preparasi Ekstrak Uji}

Tahap pengujian sampel diawali dengan pengukuran kadar air buah kersen yang dilanjutkan dengan ekstraksi dan skrining fitokimia. Pengukuran kadar air dilakukan pada 2,18 g sampel basah sehingga didapat berat konstan 0,39 g. Hasil kadar air dalam sampel, yaitu sebesar $82,36 \%$ bb. Sampel selanjutnya diekstraksi dengan metode maserasi bertingkat dengan menggunakan pelarut n-heksan, etil asetat dan etanol. Berdasarkan hasil maserasi tersebut, maka didapatkan ekstrak pekat n-heksan sebanyak 2,16 g, ekstrak etil asetat sebanyak 4,52 g dan ekstrak pekat etanol sebanyak 50,25 g. Terhadap ketiga ekstrak dilakukan uji fitokimia flavonoid dan fenol dengan memperhatikan reaksi warna yang ditimbulkan tiap pereaksi. Perubahan warna terjadi karena adanya resonansi senyawa aromatik pada fenol ataupun flavonoid (Harborne, 1996). Hasil penapisan fitokimia dapat dilihat pada Tabel 1. Ekstrak yang positif flavonoid dan fenolik selanjutnya ditentukan uji total fenol, uji total flavonoid dan aktifitas antioksidannya.

\section{Total Fenol dan Total Flavonoid Ekstrak Kasar Buah Kersen}

Pengukuran total fenol dan flavonoid buah kersen dilakukan terhadap ekstrak etil asetat dan etanol. Pengukuran total fenol dilakukan dengan prinsip Folin Ciocalteu tereduksi oleh gugus hidroksi, sedangkan pengukuran pada total flavonoid digunakan dengan prinsip $\mathrm{AlCl}_{3}$ yang akan menimbulkan reaksi kompleks dengan senyawa flavonoid (Ukieyanna, 2012). Hasil analisis kandungan total fenol dan flavonoid pada ekstrak etil asetat dan etanol dipaparkan pada Tabel 2 dan Tabel 3.

Berdasarkan Tabel 2 dan Tabel 3, diketahui hasil total senyawa fenol pada ekstrak etil asetat yaitu 0,85\% GAE dengan nilai total flavonoidnya hanya $0,03 \% \mathrm{QE}$ sedangkan pada ekstrak etanol terdapat 0,2386\% GAE dan 0,1344\% QE.

Kandungan total polifenol lebih banyak teridentifikasi pada ekstrak etil asetat diduga karena pengaruh pelarutnya. Pelarut etil asetat digunakan terlebih dahulu sebelum penggunaan etanol sehingga senyawa polifenol lebih banyak terekstrak pada etil asetat. Nilai kandungan total senyawa flavonoid pada tiap ekstrak yang dibandingkan dengan total senyawa fenol memiliki nilai lebih kecil, kemungkinan diduga karena besarnya kandungan polifenol pada tiap ekstrak tidak semuanya merupakan senyawa flavonoid, karena selain flavonoid senyawa yang merupakan golongan polifenol beberapa diantaranya adalah tanin, lignin, melanin dan fenil propanoid (Ukieyanna, 2012).

Tabel 1. Hasil Penapisan Fitokimia

\begin{tabular}{llll}
\hline Ekstrak & Pereaksi & Perubahan dengan hasil pereaksi & Hasil Uji \\
& & & \\
\hline n-heksan & $\mathrm{Mg}-\mathrm{HCl}$ & Hijau tua-hijau keruh & - Flavonoid \\
& $\mathrm{NaOH} 10 \%$ & Hijau tua-hijau muda & - Flavonoid \\
& $\mathrm{FeCl}_{3}$ & Tidak ada perubahan & - Flavonoid \\
\hline Etil Asetat & $\mathrm{Mg}-\mathrm{HCl}$ & Hijau kekuningan - oranye kemerahan & + Flavonoid \\
& $\mathrm{NaOH} \mathrm{10 \%}$ & Hijau kekuningan - coklat pekat & + Flavonoid \\
& $\mathrm{FeCl}_{3}$ & Hijau kekuningan - Hitam & + Flavonoid \\
\hline Etanol & $\mathrm{Mg}-\mathrm{HCl}$ & Oranye - Jingga kemerahan & + Flavonoid \\
& $\mathrm{NaOH} \mathrm{10 \%}$ & Oranye - Coklat & + Flavonoid \\
& $\mathrm{FeCl}_{3}$ & Oranye - Hitam & + Flavonoid \\
\hline
\end{tabular}

Tabel 2. Kandungan Total Fenol Ekstrak Buah Kersen

\begin{tabular}{lccccccc}
\hline \multicolumn{1}{c}{$\begin{array}{c}\text { Kode } \\
\text { Sampel }\end{array}$} & $\begin{array}{c}\text { Berat } \\
\text { Sampel } \\
(\mathrm{mg})\end{array}$ & $\begin{array}{c}\text { Konsentrasi } \\
\text { sampel awal } \\
(\mathrm{mg} / 5 \mathrm{~mL})\end{array}$ & & Abs & $\begin{array}{c}\text { Konsentrasi } \\
(\mathrm{x})(\mathrm{mg} / \mathrm{ml})\end{array}$ & $\begin{array}{c}\text { Faktor } \\
\text { pengenceran }\end{array}$ & \multicolumn{2}{c}{ Kadar Fenol GAE } \\
\hline Etanol & 129,50 & 25,90 & 0,35 & 6,18 & & & $\mathrm{mg} / 100 \mathrm{~g}$ \\
Etil asetat & 124,70 & 24,94 & 0,16 & 2,18 & 100 & 0,24 & 238,6 \\
\hline
\end{tabular}

Keterangan: GAE : Galic Acid Equivalent

Abs : Absorbansi 
Tabel 3. Kandungan Total Flavonoid Ekstrak Buah Kersen

\begin{tabular}{ccccccccc}
\hline $\begin{array}{c}\text { Kode } \\
\text { Sampel }\end{array}$ & $\begin{array}{c}\text { Berat } \\
\text { Sampel } \\
(\mathrm{mg})\end{array}$ & $\begin{array}{c}\text { Konsentrasi } \\
\text { sampel awal } \\
(\mathrm{mg} / 5 \mathrm{~mL})\end{array}$ & Abs & $\begin{array}{c}\text { Konsentrasi } \\
(\mathrm{x})(\mathrm{mg} / \mathrm{ml})\end{array}$ & $\begin{array}{c}\text { Faktor } \\
\text { pengenceran }\end{array}$ & \multicolumn{2}{c}{\begin{tabular}{c} 
Kadar Flavonoid \\
\cline { 7 - 8 }
\end{tabular}} \\
\hline Etanol & 107,50 & 21,50 & 0,55 & 14,44 & 2 & 0,13 & 134,4 \\
Etil asetat & 161,40 & 32,28 & 0,38 & 9,68 & 1 & 0,03 & 29,9 \\
\hline
\end{tabular}

Keterangan : QE : Quarcetin Equivalen

Abs : Absorbansi

\section{Aktivitas Antiradikal Ekstrak Buah Kersen dengan Metode DPPH}

Pengujian aktivitas antioksidan dilakukan pada ekstrak yang positif mengandung flavonoid yaitu ekstrak etil asetat dan etanol. Aktivitas antioksidan diukur dengan metode DPPH, sehingga diketahui persen peredaman atau persen inhibisi. Nilai persen inhibisi diplot terhadap konsentrasi dalam bentuk kurva sehingga didapatkan persamaan regresi yang digunakan dalam menghitung nilai $\mathrm{IC}_{50}$.

Nilai $\mathrm{IC}_{50}$ merupakan nilai yang menyatakan penghambatan senyawa yang berpotensi antioksidan terhadap radikal bebas sebesar 50\%. Nilai aktivitas antioksidan pada ekstrak etanol dan etil asetat, secara rinci dapat dilihat pada Tabel 4 dan Tabel 5. Pada penentuan aktivitas antioksidan ekstrak kersen, reaksi senyawa aktif antioksidan pada ekstrak kersen dengan radikal bebas DPPH dapat dilihat dengan adanya peluruhan warna pada DPPH dari ungu menjadi kuning. Peluruhan warna tersebut mengidentifikasikan adanya peningkatan kemampuan antioksidan dalam menangkap radikal bebas (Prakash, 2001) .
Berdasarkan Tabel 4 dan Tabel 5 dapat disimpulkan bahwa etil asetat memiliki nilai aktivitas antioksidan dengan nilai $\mathrm{IC}_{50}$ sebesar $0,13 \mathrm{mg} / \mathrm{mL}$ (130 ppm) yang artinya jauh lebih kuat dibandingkan dengan ekstrak etanol yang berkisar $0,25 \mathrm{mg} / \mathrm{mL}$ (250 ppm).

Perbedaan aktivitas antioksidan pada kedua ekstrak diduga karena adanya perbedaan kadar polifenol dan flavonoid pada masingmasing ekstrak (Tabel 2 dan Tabel 3). Aktivitas antioksidan pada ekstrak etil asetat memiliki nilai yang lebih kuat karena banyaknya kandungan fenol yang terdapat pada ekstrak etil asetat dibandingkan pada ekstrak etanol. Hasil tersebut menunjukkan bahwa polifenol pada ekstrak buah kersen memilki aktivitas yang baik sebagai senyawa yang berpotensi sebagai antioksidan. Kemampuan senyawa tersebut didukung dalam penelitian golongan senyawa fenolik yang terdapat dalam hasil isolasi kulit batang kersen sebagai antioksidan (Alista, 2011).Sifat fenol sebagai salah satu senyawa yang bersifat sebagai antioksidan karena dapat mendonorkan atom hidrogen dari hidroksi pada senyawa radikal sehingga senyawa radikal dapat bersifat lebih stabil (Prakash, 2001) .

Tabel 4. Hasil Uji Aktivitas Antioksidan Ekstrak Etanol

\begin{tabular}{|c|c|c|c|c|c|c|}
\hline \multirow{2}{*}{$\begin{array}{c}\text { Konsentrasi } \\
\mathrm{mg} / \mathrm{mL}\end{array}$} & \multicolumn{2}{|c|}{ Absorbansi } & \multirow{2}{*}{$\begin{array}{l}\text { Persen } \\
\text { Inhibisi }\end{array}$} & \multirow{2}{*}{$\begin{array}{c}\text { Persamaan } \\
\text { Regresi }\end{array}$} & \multirow{2}{*}{$\begin{array}{l}\text { Nilai } \mathrm{IC}_{50} \\
(\mathrm{mg} / \mathrm{mL})\end{array}$} & \multirow{2}{*}{$\begin{array}{l}{\text { Nilai } \mathrm{IC}_{50}}(\mathrm{ppm})\end{array}$} \\
\hline & Sampel & Blanko & & & & \\
\hline 0,05 & 0,452 & \multirow{4}{*}{0,513} & 11,89 & \multirow{4}{*}{$\begin{array}{c}Y=194,84 x \\
\quad+0,4397\end{array}$} & \multirow{4}{*}{0,25} & \multirow{4}{*}{250} \\
\hline 0,10 & 0,416 & & 18,91 & & & \\
\hline 0,20 & 0,319 & & 37,82 & & & \\
\hline 0,25 & 0,254 & & 50,49 & & & \\
\hline
\end{tabular}

Tabel 5. Hasil Uji aktivitas Antioksidan Ekstrak Etil Asetat

\begin{tabular}{ccccccc}
\hline $\begin{array}{l}\text { Konsentrasi } \\
\mathrm{mg} / \mathrm{mL}\end{array}$ & \multicolumn{2}{c}{ Absorbansi } & $\begin{array}{l}\text { Persen } \\
\text { Inhibisi }\end{array}$ & $\begin{array}{l}\text { Persamaan } \\
\text { Regresi }\end{array}$ & $\begin{array}{l}\text { Nilai IC } 50 \\
(\mathrm{mg} / \mathrm{mL})\end{array}$ & $\begin{array}{l}\text { Nilai } \mathrm{IC}_{50} \\
(\mathrm{ppm})\end{array}$ \\
\cline { 2 - 6 } 0,05 & Sampel & Blanko & & & & \\
0,10 & 0,394 & & 23,20 & & & \\
0,20 & 0,114 & 0,513 & 39,57 & $\mathrm{Y}=356,09 \mathrm{x}$ & 0,13 & 130 \\
0,25 & 0,059 & & 77,78 & $+3,0781$ & & \\
\hline
\end{tabular}




\section{SIMPULAN DAN SARAN}

\section{Simpulan}

Berdasarkan hasil penelitian yang telah dilakukan maka dapat disimpulkan bahwa ekstrak etanol dan etil asetat memiliki kandungan total fenol berturut turut yaitu $0,24 \%$ GAE dan $0,85 \%$ GAE sedangkan kandungan flavonoidnya yaitu sebesar $0,13 \%$ QE dan 0,03\% QE. Uji aktivitas antioksidan pada ekstrak etil asetat dan etanol yang diukur dengan metode DPPH dinyatakan dengan nilai $\mathrm{IC}_{50}$ sebesar $0,13 \mathrm{mg} / \mathrm{mL}$ dan $0,25 \mathrm{mg} / \mathrm{mL}$.

\section{Saran}

Adapun hal yang dapat disarankan dari penelitian ini yaitu perlu dilakukan penelitian mengenai isolasi senyawa aktif antioksidan pada ekstrak buah kersen dan mengidentifikasi senyawa aktif tersebut untuk mengetahui golongan dan struktur dari senyawa aktif yang berpotensi sebagai antioksidan.

\section{UCAPAN TERIMAKASIH}

Penulis mengucapkan terimakasih kepada bapak Dr. I Wayan Gede Gunawan, S.Si., M.Si., ibu Dra. Ida Ayu Raka Astiti Asih, M.Si., ibu Ni Komang Ariati, S.Si., M.P., bapak Dr. I Nengah Wirajana, S.Si., M.Si, dan bapak Putu Suarya, S.Si, M.Si atas segala saran dan masukan dalam penulisan karya ilmiah ini. Penulis juga mengucapkan terimakasih kepada keluarga dan teman-teman angkatan 2013 untuk segala dukungan dan bantuannya.

\section{DAFTAR PUSTAKA}

Alista, Mela., 2011, Isolasi, Identifikasi, dan Uji Aktivitas Antioksidan Senyawa Fenolik dari Kulit Batang Kersen (Muntingia calabura), Skripsi, Fakultas Sains dan Teknologi, Universitas Airlangga

Anonim., 2012, Herbal Indonesia Berkhasiat Bukti Ilmiah dan Cara Racik, TRUBUS, Depok

Blois, M.S., 1958, Antioxidant Determinations by The Use of A Stable Free radical, Nature, 181: 1199-1200

Chang C.Y.M. and Wen., 2002. Estimation of Total Flavonoid in Propolis by Two Complymentary

Colorimetric
Methods, Journal Food Drug Anal, 178-182.

Dwiyanti, P., Sri, R., dan Umar, S., 2010, Aktivitas Antioksidan Dan Kadar Senyawa Fenolik Pada Kunir Putih (Curcuma mangga Val) Segar Dan Setelah Blanching, Jurnal Agritech, 30 (2).

Halliwel., 1991, Reactive Oxygen Species in Living System: Source, Biochemistry, and Role in Human Disease, Am $J$ Med, 91: 14-22.

Hany, Anastasia, M., 2016, Uji Aktivitas Antioksidan Senyawa Flavonoid pada Kulit Batang Tumbuhan Gayam (Inocarpus fagiferus Fosb),Jurnal Kimia, 10 (1): 15-22

Harborne, J.B., 1996, Metode Fitokimia Penuntun Cara Modern Menganalisa Tumbuhan. Terbitan kedua, Penerbit ITB, Bandung.

Hertiani, T., Pramono.S., Supardjan., 2000, Uji Daya Antioksidan Senyawa Flavonoid Daun Plantago Major L, Majalah Farmasi Indonesia, 11, (4): 234

Kunwar, A., and Priyadarsini K.I., 2011, Free Radicals, Oxidatives Stress And Importance of Antioxidants in Human Health, J.Med Allied Sci., 1(2): 53-60.

Miller. A.L., 1996, Antioxidant Flavonoid : Structure, Function, And Clinical Usage, Alt Med Rev., 1(2): 103-104.

Panosvka, T.K., Kulevanova, S., and Stefova., 2005, In Vitro Antioxidant Activity of Some Teucrium Spesies (Lamiceae), Act Pharm, 55: 207-215.

Prakash A., 2001, Antioxidant Activity. Medailion Laboratories Analitical Progress, 19: 21-24.

Rauf dan Rusdin., 2015, Kimia Pangan, ANDI, Yogyakarta.

Riaminati, K., Amna, H., dan Mulayani, S., 2016, Studi Kapasitas dan Sinergisme Antioksidan Pada Ekstrak Kunyit (Curcuma domestica Val.) Dan Daun Asam (Tamarindus indica L.), Jurnal Rekayasa dan Managemen Agroindustri, 4 ( 3): 93-104.

Sibuea, P., 2003, Antioksidan Senyawa Ajaib Penangkal Penuaan Dini, Sinar Harapan, Yogyakarta.

Ukieyanna, E., 2012. Aktivitas Antioksidan, Kadar Fenolik, dan Flavonoid Total Tumbuhan Suruhan (Peperomia pellucida L. Kunth), Skripsi, Fakultas Matematika 
Uji Kandungan Total Fenol Dan Flavonoid Dari Buah Kersen (Muntingia calabura) serta Aktivitas Antioksidannya (Made Ratih Mettaswari Senet, I Made Oka Adi Parwata dan I Wayan Sudiarta)

dan Ilmu Pengetahuan Alam Institut Pertanian Bogor, Jawa Barat.

Widodo, M.A., 1997, Xenobiotika dan Radikal Bebas pada Patogenesis Penyakit dalam Makalah Seminar dan Loka Karya, Fakultas Kedokteran Brawijaya, Malang, 19-22
Yunahara, F., Setyorini, S., dan Witha, L.S., 2009, Uji Aktivitas Antioksidan pada Buah Talok dengan Metode DPPH dan Rancimat dalam Seminar PATPI, Fakultas Farmasi Universitas Pancasila, Jakarta, 9-16 